A GAS PIPETTE.

By P. G. Agnew.

Pontiac, Mich.

Having noticed in the March number of School Science and Mathematics the description by Mr. J. A. Griffin of an apparatus for transmitting gas from one vessel to another, it has occurred to me that the form of gas pipette here figured may be of interest. The bulbs and tips are immersed in the water, or other fluid, and the bulb $A$ filled by suction, ( $B$ does not fill at first.) The water is then forced from $A$ into $B$, the tip brought under the vessel containing the gas to be transferred, and $B$ filled with gas. A scratch at $c$ allows the same quantity to be taken each time. It would be more convenient to have $B$ made to hold 5 or $10 \mathrm{~cm}^{3}$. If desired, a drop of water may be drawn into the tip to prevent the gas from being contami-

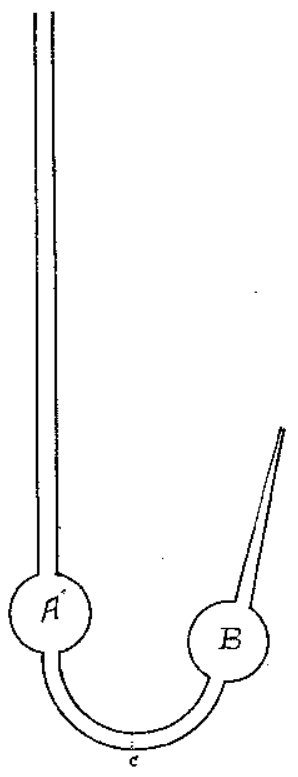
nated by air.

I have found that elementary students learn to use the instrument without trouble.

Perhaps the form is already in use but $I$ have not seen it described.

\title{
A SIMPLE ACID AND ALKALI-PROOF LABEL FOR REAGENT BOTTLES.
}

By E. P. SchOCH. University of Texas, Austin.

The accompanying cut shows reagent bottles which, together with some three hundred others, were labeled three years ago and have been in constant use ever since. All of them have withstood exposure to concentrated acids and alkalis and mechanical wear and tear satisfactorily.

The labels were printed with rubber stamps direct on the 